Article

\title{
Freshwater Plants Synthesize Sulfated Polysaccharides: Heterogalactans from Water Hyacinth (Eicchornia crassipes)
}

\author{
Nednaldo Dantas-Santos ${ }^{1,2}$, Dayanne Lopes Gomes ${ }^{1}$, Leandro Silva Costa ${ }^{1}$, \\ Sara Lima Cordeiro ${ }^{\mathbf{1}}$, Mariana Santos Santana Pereira Costa ${ }^{\mathbf{1}}$, Edvaldo Silva Trindade ${ }^{\mathbf{3}}$, \\ Célia Regina Chavichiolo Franco ${ }^{3}$, Kátia Castanho Scortecci ${ }^{4}$, Edda Lisboa Leite ${ }^{5}$ and \\ Hugo Alexandre Oliveira Rocha ${ }^{1,2, *}$
}

1 Laboratory of Biotechnology of Natural Polymers (BIOPOL), Department of Biochemistry, Federal University of Rio Grande do Norte (UFRN), Natal-RN 59078-970, Brazil;

E-Mails: nednaldod@hotmail.com (N.D.-S.); dayanne_gomes@hotmail.com (D.L.G.);

leandro-silva-costa@hotmail.com (L.S.C); sara-cordeiro@hotmail.com (S.L.C.); marispc_bio@yahoo.com.br (M.S.S.P.C.)

2 Health Post-Graduate Program, Federal University of Rio Grande do Norte (UFRN), Natal-RN 59078-970, Brazil

3 Department of Cell Biology, Federal University of Parana (UFPR), Curitiba-PR 81531-990, Brazil; E-Mails: estrindade@ufpr.br (E.S.T.); crcfranc@ufpr.br (C.R.C.F)

4 Department of Cell Biology and Genetic, Federal University of Rio Grande do Norte (UFRN), Natal-RN 59078-970, Brazil; E-Mail: kacscort@yahoo.com

5 Laboratory of Glycobiology, Department of Biochemistry, Federal University of Rio Grande do Norte (UFRN), Natal-RN 59078-970, Brazil; E-Mail: eddaleite@cb.ufrn.br

* Author to whom correspondence should be addressed; E-Mail: hugo@cb.ufrn.br; Tel.: +55-84-32153416 ext. 207; Fax: +55-84-32119208.

Received: 28 November 2011; in revised form: 30 December 2011 / Accepted: 6 January 2012 / Published: 17 January 2012

\begin{abstract}
Sulfated polysaccharides (SP) are found mainly in seaweeds and animals. To date, they have only been found in six plants and all inhabit saline environments. Furthermore, there are no reports of SP in freshwater or terrestrial plants. As such, this study investigated the presence of SP in freshwaters Eichhornia crassipes, Egeria densa, Egeria naja, Cabomba caroliniana, Hydrocotyle bonariensis and Nymphaea ampla. Chemical analysis identified sulfate in N. ampla, H. bonariensis and, more specifically, E. crassipes. In addition, chemical analysis, FT-IR spectroscopy, histological analysis, scanning electron microscopy (SEM) and energy-dispersive X-ray analysis (EDXA), as
\end{abstract}


well as agarose gel electrophoresis detected SP in all parts of E. crassipes, primarily in the root (epidermis and vascular bundle). Galactose, glucose and arabinose are the main monosaccharides found in the sulfated polysaccharides from E. crassipes. In activated partial thromboplastin time (APTT) test, to evaluate the intrinsic coagulation pathway, SP from the root and rhizome prolonged the coagulation time to double the baseline value, with $0.1 \mathrm{mg} / \mathrm{mL}$ and $0.15 \mathrm{mg} / \mathrm{mL}$, respectively. However, SP from the leaf and petiole showed no anticoagulant activity. Eichornia SP demonstrated promising anticoagulant potential and have been selected for further studies on bioguided fractionation; isolation and characterization of pure polysaccharides from this species. Additionally in vivo experiments are needed and are already underway.

Keywords: freshwater; biological activities; sulfated galactan

\section{Introduction}

Sulfated polysaccharides (SP) from different sources have been studied in the light of their important pharmacological activities, such as anticoagulant, antioxidant, antiproliferative, antitumoral, anticomplementary, anti-inflammatory, and antiviral properties [1]. Anticoagulant activity is among the most widely studied properties of sulfated polysaccharides. Unfractionated and low molecular weight heparins are the only sulfated polysaccharides currently used as anticoagulants. However, these compounds have several side effects including bleeding and thrombocytopenia, increasing the need to search for alternative sources of anticoagulant agents, such as other SP.

SP are found mainly in marine seaweeds [2] and the animal kingdom [3]. Sulfated glycosaminoglycans (GAGs) are the best-known animal SP. They are polydisperse linear polysaccharides composed of alternate units of hexosamine and uronic acid, connected by glycosidic linkages. Sulfation takes place at different positions of the disaccharide units. Almost all GAGs occur in tissues as proteoglycans (PGs), where the polysaccharide chains are covalently linked to a core protein [4]. GAGs display peculiar structural variability according to tissue and species. Considering their cellular localization, structural diversity, and expression changes during different physiological conditions, including cell division, cell growth, cell adhesion, cell migration, cell differentiation, etc., then this raises the hypothesis that PGs and GAGs play a specific role in cellular interactions.

In seaweeds, SP are found in the extracellular matrix. Their physiological function in seaweeds remains little known, although some authors suggest they protect against dehydration occurring at low tide. This would explain the higher SP content of seaweeds at inter-tidal level [5]. The SP structures depend on the seaweed classes Rhodophyceae, Phaeophyceae and Chlorophyceae. The most well known SP in Rhodophyceae are carragenans and agarans, which are sulfated galactans [6]. SP from brown Phaeophyceae are homo- and hetero-polysaccharides containing $\alpha$-L-sulfated fucose called fucan and fucoidan, respectively [7]. SP found in Chlorophyceae are usually heteropolysaccarides containing xylose, galactose, arabinose, mannose, glucuronic acid or glucose. However, there is a predominance of one monosaccharide at the expense of others in several algal orders [8]. 
Since SP in seaweeds and animals may participate in and regulate many cellular events and physiological processes in several organisms displaying tissue organization [2,3], many researchers believe SP could also occur in other types of organisms with tissue organization. However, there are no studies showing fungi synthesizing SP and only recently Aquino and colleagues confirmed the presence of SP in plants, namely three species of marine angiosperms, Ruppia maritima, Halodule wrightii and Halophila decipiens, and two species of mangrove, Avicennia schaueriana and Rhizophora mangle. However, the authors did not find SP in terrestrial plants Zea mays (corn), Oryza sativa (rice) or Phaseolus vulgaris (bean); neither did they investigate SP in freshwater plants $[9,10]$.

In the eighties, Nader and colleagues studied 15 species of invertebrate groups including Crustacea, Pelecypoda and Gastropoda, and recorded a positive correlation between sulfated polysaccharide concentrations and water salinity in these aquatic invertebrates [11]. In addition, SP synthesized in marine angiosperm Ruppia maritima was not found when the plant was cultivated in fresh water [10]. Thus, the question, do freshwater plants actually synthesize SP?

In order to understand this question, the present study used different tools such as chemical and histological analyses, energy-dispersive X-ray analysis (EDXA), gel electrophoresis and infra-red spectroscopy to confirm the presence of sulfated polysaccharides in freshwater plants for the first time. Moreover, we also demonstrate that SP extracted from E. crassipes root has potential as an anticoagulant compound.

\section{Results and Discussion}

\subsection{Identification of Freshwater Plants That Synthesize Sulfated Polysaccharides}

Abiotic factors can affect the physical and chemical characteristics of river water, which can, in turn, affect molecular synthesis in plants. Salinity has been suggested as a factor that may induce SP production in animals and seaweeds $[10,11]$. As such, we selected a river containing several species of freshwater plants and low or no salinity as our collection point, namely the Agua Quente stream. Several abiotic parameters were analyzed. Average rainfall was $252.0 \mathrm{~mm} / \mathrm{month}$ and sun exposure was $248.20 \mathrm{~h}$ per month. During analysis, average water temperature in the stream remained around $32{ }^{\circ} \mathrm{C}$. We also recorded an absence of salinity and no changes in water depth during the sampling period.

Seven freshwater plants were collected in the Agua Quente stream: Eichhornia crassipes, Egeria densa, Egeria cobra, Cabomba caroliniana, Ceratophyllum aquaticum, Hydrocotyle bonariensis and Nymphaea ample. These were collected and divided into root, rhizome, petiole, leaf, and flower, when possible. Each portion was submitted separately for polysaccharide extraction as described in Methods. Polysaccharides; from each plant, portions were obtained after proteolysis and precipitation with methanol. Chemical analysis showed the presence of sulfate and polysaccharides in three from the seven plants analyzed as presented at Table 1. No preference was found for sulfate specific location in plant tissue. $N$. ampla showed higher amounts of sulfate in the root, H. bonariensis in leaves and E. crassipes in petiole and root. However, we still detected levels of proteins in our preparation. In order to rule out the possibility that the sulfate in some samples could be derived from the proteins, but not polysaccharides, the proteins in the samples were precipitated with trichloroacetic 
acid (TCA) (80\%). Then, the amount of sulfate and proteins in the samples was re-determined and the data showed that the amount of sulfate did not change after TCA treatment (data not shown). Additionally, we did not detect any protein in all of the samples analyzed.

Table 1. Mass/mass ratio of total sugars, sulfate and proteins extracted from different portions of plants.

\begin{tabular}{llccc}
\hline Plant & Portion & Polysaccharides & Sulfate & Protein \\
\hline \multirow{2}{*}{ Eichhornia crassipes (Mart.) Solms. } & Root & 1.00 & 0.240 & 0.15 \\
& Rhizome & 1.00 & 0.140 & 0.11 \\
& Petiole & 1.00 & 0.340 & 0.20 \\
& Leave & 1.00 & 0.060 & 0.19 \\
\hline \multirow{2}{*}{ Egeria densa Planchon } & Root & 1.00 & - & 0.04 \\
& Petiole & 1.00 & - & 0.02 \\
\multirow{2}{*}{ Egeria naja Planchon } & Leave & 1.00 & - & 0.02 \\
\hline \multirow{2}{*}{ Cabomba caroliniana Gray } & Stem & 1.00 & - & 0.05 \\
& Leave & 1.00 & - & 0.06 \\
\hline \multirow{2}{*}{ Ceratophyllum aquaticum Lam. } & Stem & 1.00 & - & 0.05 \\
& Leave & 1.00 & - & 0.06 \\
\hline \multirow{2}{*}{ Hydrocotyle bonariensis Comm. ex Lam. } & Root & 1.00 & - & 0.01 \\
& Stem & 1.00 & - & 0.08 \\
& Leave & 1.00 & - & 0.11 \\
\hline & Root & 1.00 & - & 0.03 \\
& Petiole & 1.00 & 0.010 & 0.04 \\
Nymphaea ampla (Salisb.) D.C. & Leave & 1.00 & 0.290 & 0.06 \\
\hline & Root & 1.00 & 0.240 & 0.06 \\
& Rhizome & 1.00 & 0.040 & 0.13 \\
& Petiole & 1.00 & 0.003 & 0.11 \\
& Leave & 1.00 & 0.008 & 0.01 \\
& Flower & 1.00 & 0.020 & 0.04 \\
\hline
\end{tabular}

Chemical data obtained showed that three of the seven plants collected in fresh water contained SP (E. crassipes, H. bonariensis and $N$. ampla). This indicates SP is more common in plants than previously thought. Since $E$. crassipes exhibited the highest amount of sulfate in comparison to other plants, it was chosen for the next set of experiments.

\subsection{Characterization of Sulfated Polysaccharides from E. crassipes}

E. crassipes, more commonly known as aguape (Brazil) or water hyacinth (USA), has been studied by other groups, but has never been investigated for the presence of SP. As such, percentage composition was analyzed for comparison with previous proximate composition determination, since it may have been different. Proximate composition of E. crassipes portions (leaves, petioles, rhizome and roots) is shown in Table 2. All parts displayed low lipid and nitrogen contents. Moisture values ranged from 86 (leaves) to 93 (petiole and rhizome), with no significant differences ( $p>0.05$ ) among replicates. No significant differences were recorded when comparing the percentage of carbohydrates in the four 
plant sections. The highest ash content was found in the root and rhizome, while the largest percentage of protein was observed in the petioles and leaves.

Table 2. Proximate composition of root, rhizome, petiole, and leaf of E. crassipes.

\begin{tabular}{lcccr}
\hline Compound & Root & Rhizome & Petiole & Leaf \\
\hline Carbohydrate (\%) & 13.6 & 13.7 & 13.6 & 11.9 \\
Ash (\%) & 14.6 & 13.6 & 6.6 & 5.9 \\
Protein (\%) & 9.1 & 8.9 & 13.7 & 13.9 \\
Lipids (\%) & 1.1 & 1.6 & 3.0 & 1.5 \\
Moisture (\%) & 91.3 & 93.2 & 93.2 & 86.5 \\
Nitrogen (\%) & 1.5 & 1.4 & 2.2 & 2.2 \\
\hline
\end{tabular}

Data obtained for different portions of E. crassipes (Table 2) was comparable to that recorded in prior research [12]. This confirms that E. crassipes used here is similar to that previously investigated.

Monosaccharide compositions (Table 3) from E. crassipes polysaccharide showed that galactose, glucose, arabinose, xylose are present in all parts. In addition, mannose and xylose were also found in the root and rhizome. Galactose was the main monosaccharide in polysaccharide fractions from E. crassipes.

Table 3. Monosaccharide composition of sulfated polysaccharides extracted from E. crassipes.

\begin{tabular}{lccccc}
\hline \multirow{2}{*}{ Portion } & \multicolumn{3}{c}{ Molar } & Ratio \\
\cline { 2 - 6 } & Gal $^{\mathbf{1}}$ & Glc $^{\mathbf{1}}$ & Ara $^{1}$ & Xyl $^{\mathbf{1}}$ & Man $^{\mathbf{1}}$ \\
\hline Root & 1.0 & 0.5 & 0.3 & 0.1 & 0.3 \\
Rhizome & 1.0 & 0.4 & 0.7 & 0.1 & 0.1 \\
Petiole & 1.0 & 0.5 & 0.6 & - & - \\
Leaf & 1.0 & 1.0 & 1.0 & - & - \\
\hline
\end{tabular}

${ }^{1}$ Molar ratio of sugars using galactose as parameter. Gal, galactose; Glc, glucose; Ara, arabinose; $X y l$, xylose; Man, mannose.

No amino sugars were identified in the monosaccharide composition of SP in E. crassipes. This result refutes the hypothesis that $E$. crassipes may be capable of synthesizing glycosaminoglycans as occurs in animals. Furthermore, fucose, a sugar type found primarily in brown seaweeds, was not present. Monosaccharide composition also indicated the presence of galactose, as well as small amounts of glucose and arabinose. SP with a similar composition are observed in green seaweed [8], although sulfated homogalactans have also been described [13]. Sulfated homogalactans have been characterized in SP from the seagrass $R$. maritima, $H$. decipiens, $H$. wrightii [9], while those in mangroves were sulfated arabinogalactans. These data demonstrate that SP in E. crassipes are more similar to those found in other plants and in green seaweeds than those produced by brown seaweeds and animals.

Characteristic sulfate absorptions were identified in the all FT-IR spectra of E. crassipes polysaccharides: bands approximately $1252 \mathrm{~cm}^{-1}$ for an asymmetric $\mathrm{S}=\mathrm{O}$ stretching vibration [14]; bands around $1068-1167 \mathrm{~cm}^{-1}$ were assigned mainly to symmetric $\mathrm{O}=\mathrm{S}=\mathrm{O}$ stretching vibration of sulfate esters [14] found in all spectra. Bands around $820 \mathrm{~cm}^{-1}$ were recorded in all spectra, indicating that sulfate groups are located at position six of the galactose ring $[15,16]$. Additionally, at $3000-3400 \mathrm{~cm}^{-1}$ 
and around $2920 \mathrm{~cm}^{-1}$ all polysaccharides showed signs of the stretching vibration $\mathrm{O}-\mathrm{H}$ and $\mathrm{C}-\mathrm{H}$, respectively. Bands at about $1638-1654 \mathrm{~cm}^{-1}$ were due to bound water [16].

\subsection{Polysaccharide Analysis by Agarose Gel Electrophoresis}

In order to verify whether sulfate ions were linked to polysaccharides, SP were subjected to electrophoresis in agarose gel. Gels were dried and stained with toluidine blue. Using this dye, polysaccharides are stained purple, as with the GAGs heparan, chondroitin and dermatan sulfate (Figure 1). However, purple bands were not observed in the leaves and rhizome fractions of E. crassipes. Moreover, the root portion showed polydisperse band, purple staining, indicating the presence of sulfated polysaccharides (Figure 1) and the petiole displayed a small purple band with low electrophoretic mobility, since it did not move from the gel line.

Figure 1. Electrophoresis of sulfated polysaccharides from E. crassipes. Aliquots of approximately $5 \mu \mathrm{L}(250 \mu \mathrm{g})$ of Eicchonia polysaccharides or $(5 \mu \mathrm{g})$ glycosaminoglycans were applied in agarose gel $(10 \times 7.5 \mathrm{~cm}$, and $0.2 \mathrm{~cm}$ thick $)$ prepared in $0.05 \mathrm{M}$ 1,3-diaminopropane-acetate buffer $\mathrm{pH} 9.0$, and subjected to electrophoresis at $110 \mathrm{~V} / \mathrm{cm}$ for $60 \mathrm{~min}$. Gels were then held in $0.1 \%$ cetyltrimethylammonium bromide for $2 \mathrm{~h}$ and dried. Polysaccharides were stained with $0.1 \%$ toluidine blue in a solution containing $50 \%$ ethanol and $1 \%$ acid acetic, in water, for $15 \mathrm{~min}$. Gels were then de-stained using the same solution, without toluidine blue. R-root; Ri-rizhome; Pet-petiole; L-leaf; CS — chondroitin sulfate; DS — dermatan sulfate; HS — heparan sulfate; Or — origin.

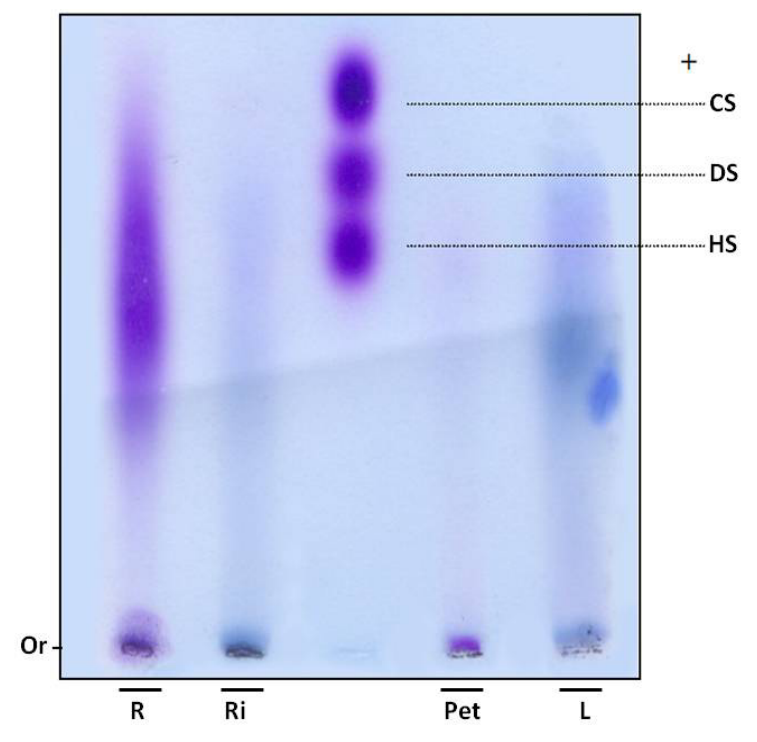

SP were confirmed in the petiole and roots by agarose gel electrophoresis. An interesting aspect is that these two portions also had a high proportion of sulfate in relation to sugar (Table 1). The 1,3-diaminopropane/acetate buffer used in electrophoresis allowed diamines to interact with sulfate groups present in SP, reducing electrophoretic mobility. This interaction also depends on conformation and consequently the composition of SP [17]. Thus chondroitin sulfate and dermatan sulfate, which have the same charge/mass ratio, have different electrophoretic mobilities in a diaminopropane/acetate buffer (Figure 1). 
Since SP from the petiole and root portions exhibited different mobility, E. crassipes may produce more than one type of SP. This finding was previously recorded in different organisms, such as invertebrates and vertebrates, as well as seaweeds. Purple bands were not detected in the rhizome and leaves. However, infrared analysis indicated these sections also produce SP, albeit probably in small amounts, given it was not detected by agarose gel methodology.

\subsection{Histological, and EDXA/MEV Analysis}

Another approach used to identify sulfated polysaccharides in this plant was histological localization analysis of each portion. For freshwater Eicchornia crasipes, sulfated polysaccharide was found primarily in the cell wall, after these sections were stained with toluidine blue and observed with optical microscopy (Figure 2). Sulfated polysaccharides were detected in the epidermis and exodermis at the cortex of the root (Figure 2A). The rhizome was also observed, exhibiting irregular cells in the cortex (marked with an arrow) and a well organized layer of cells in the epidermis (indicated by an arrow). This section also showed sulfated polysaccharides in the cortical region of the rhizome (marked with an arrow), but displayed less labeling intensity compared with the root (Figure 2B). The third area analyzed for E. crasipes was the petiole, which presented an epidermal layer of cells with uniform size similar to those found in the rhizome region. This was followed by collenchymas, composed of cells with different shapes and sizes. The epidermis and collenchymas were stained with toluidine blue, indicating the presence of sulfated compounds in these areas (Figure $2 \mathrm{C}$ ). The E. crasipes leaf is formed of a layer of cuboidal-shaped cells external to the leaf tissue, followed by successive layers of cells of varying sizes and shapes. The color of the epidermal cell layer in the leaf region suggested the presence of sulfated compounds given that it was stained by toluidine blue when compared to other regions (2D). However, as observed with the rhizome, the leaf also demonstrated less labeling intensity.

Considering all the results obtained, the rizhome portion displayed the highest amount of SP. Thus, this section was analyzed using scanning electron microscopes/Energy-dispersive X-ray spectroscopy (SEM/EDXA) in order to verify the presence of sulfur from SP. Figure 3 shows three points analyzed with this method. SEM/EDXA analysis of the plant root allowed simultaneous observation of several elements in a fast and quantitative manner (Table 4). Considering the three triplicate analyses, elements $\mathrm{C}, \mathrm{O}$ and $\mathrm{N}$, as well as smaller amounts of $\mathrm{S}$ were detected, confirming the presence of sulfate polysaccharide in E. crasipes. 
Figure 2. Sulfated polysaccharide localization in different regions of the E. crassipes determined by histological analysis. Optical microscopy images of the root (A), rhizome (B) petiole (C) and leaf (D) of the E. crassipes showed differences in the staining intensity from toluidine blue represented by the arrows.
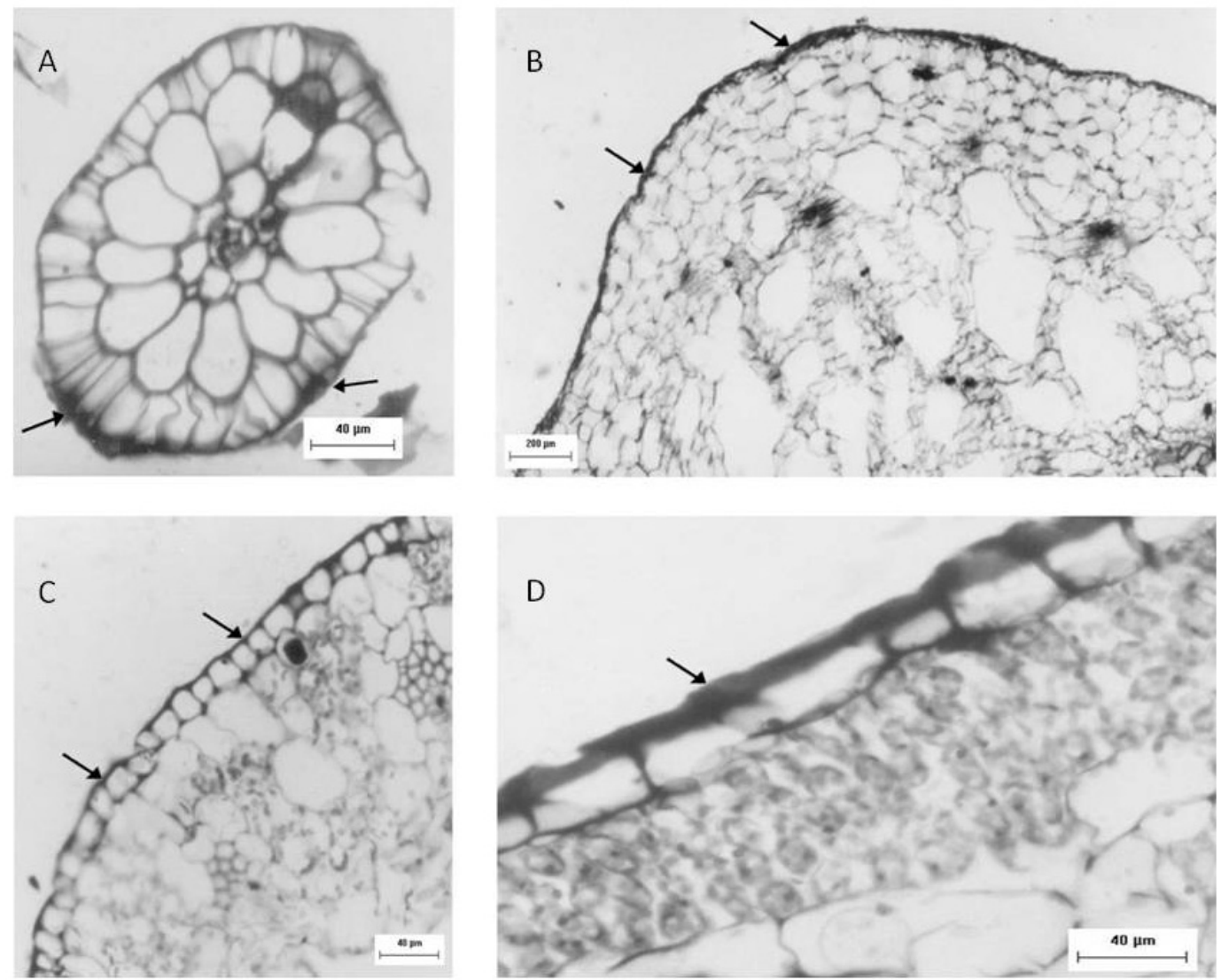

Figure 3. Scanning electron microscopy from E. crassipes root. Arrow, arrowhead, and asterisk indicate the points of collection of data for analysis of energy-dispersive X-ray analysis (EDXA). Arrow - epidermis; arrowhead — cortex; asterisk—vascular bundle.

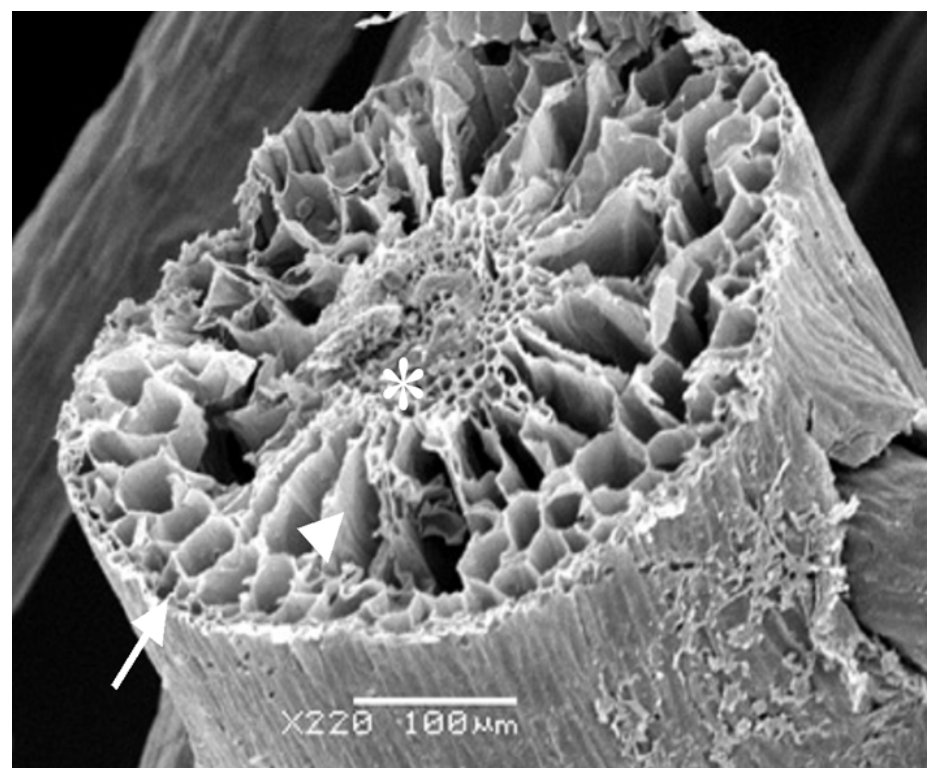


Table 4. Major components elemental surface composition of root the E. crassipes determined by SEM/EDXA.

\begin{tabular}{cccc}
\hline \multicolumn{4}{c}{ Main components (at\%) } \\
\hline Elements & Epidermis & Cortex & Vascular bundle \\
\hline C & 30.1 & 19.1 & 10.5 \\
O & 37.3 & 52.4 & 49.3 \\
N & 29.8 & 28.4 & 38.7 \\
S & 2.5 & 0.9 & 1.3 \\
\hline
\end{tabular}

Histochemical analysis identified SP in all parts analyzed. As observed in R. maritima [9], substantial amounts of SP were also found in the roots of E. crassipes. Aquino and colleagues suggested its presence in the roots may be related to the role of SP in nutrition and water capture. Results obtained by EDXA showed sulfur in the epidermis and cell wall, important regions for water and nutrient capture in plants, reinforcing the function of SP. However, what exactly is the role of SP in the leaves and petiole of E. crassipes? It has been suggested that SP in seaweeds may protect against water loss during sun exposure at low tide [5]. As such, SP may have the same function in the leaves and petiole of E. crassipes.

Aquino and colleagues cultivated the seaweed $R$. maritima in different tanks under different salinity. SP were produced in smaller amounts in $R$. maritima plants grown in low salinity and in fresh water, no SP were detected. However, in rice (O. sativa) cultivated in the presence or absence of $200 \mathrm{mM}$ of $\mathrm{NaCl}$, no SP production was observed in the presence of salinity [10]. Furthermore, our results with E. crassipes collected in a non-saline environment confirmed the presence of SP. This suggests freshwater plants may produce SP that is not related to salinity stress, and that other factors may promote their production.

\subsection{Genomic Analysis}

Considering this hypothesis and genomic tools available on web pages, an in silico analysis was conducted to identify possible sequences related to SP synthesis in plants. Since these sequences were not found in the genome database for plants and seaweeds, sequences were used from Rattus norvegicus (M92042); Homo sapiens (U17970) and Mus musculus (U02304) to design two pairs of primers at the region corresponding to 5'PSB 3'PB - that recognizes 3'-phosphoadenosine-5'-phosphosulfate (PAPS) binding motif. First, a polymerase chain reaction (PCR) amplification was performed using rat and human DNA to test the primers. Products obtained were sequenced and corresponded to these two sequences. Next, PCR amplification was carried out using E. crassipes DNA in high and low stringent PCR conditions. The resulting products obtained were cloned and sequenced. However, no sequences related to sulfotransferase were obtained. The outcome indicated these regions may be divergent in plants, given that the sequences could not be amplified.

\subsection{Anticoagulant Activity}

Several investigations have shown that SP have different biological/pharmacological activities, such as anticoagulants $[8,18]$. The present study demonstrates that E. crassipes produces SP, making it 
important to evaluate the polysaccharide bioactivity of this freshwater plant. Thus, we assessed anticoagulant activity of sulfated polysaccharide-rich extracts of E. crassipes through activated partial thromboplastin time (APTT) and protrombin time (PT) tests, which analyze the intrinsic and extrinsic pathways of coagulation, respectively. Since this is the first identification of SP in freshwater plants, we also examined anticoagulant activity in three seaweeds: Caulerpa sertularioides (green), Gracilaria caudata (red), and Dictyopteris delicatula (brown). These are known to have anticoagulation activity and as such were used for comparison with E. crassipes SP.

The anticoagulant activity is presented in Table 5. In the PT test, SP produced by E. crassipes could not alter the plasma clotting time. However, in APTT testing, several polysaccharides showed considerable anticoagulant activity. SP from $D$. delicatula was the most potent anticoagulant compound, followed by SP in the roots and leaves of E. crassipes. (Table 5). No correlation was found between anticoagulant activity and sulphate/sugar ratio $\left(R^{2}=0.201\right)$. This is in agreement with different results showing that the anticoagulant effect of SP is dependent on molecule structure and charge distribution, not only on the sulfate group [19,20]. None of the sulfated polysaccharides assayed were more active than heparin, an anticoagulant drug used as the positive control.

Table 5. Anticoagulant activity of sulfated polysaccharides from different sources.

\begin{tabular}{lccc}
\hline Sample & $\begin{array}{c}\text { Sulfate/sugar } \\
(\mathbf{w} / \mathbf{w})\end{array}$ & ${ }^{\mathbf{a}} \mathbf{P T}$ & ${ }^{\mathbf{a}}$ APTT \\
\hline SP from Root & 0.24 & $\mathrm{nd}$ & 0.100 \\
SP from Rhizome & 0.14 & nd & 0.150 \\
SP from Petiole & 0.34 & nd & nd \\
SP from Leaf & 0.06 & nd & 0.100 \\
SP from C. sertularioides & 0.85 & nd & 0.100 \\
SP from G. caudata & 0.20 & nd & nd \\
SP from D. delicatula & 0.34 & nd & 0.040 \\
Heparin & - & 0.001 & 0.002 \\
\hline
\end{tabular}

SP: sulfated polysaccharides; APTT: activated partial thromboplastin time; PT: protrombin time; nd: anticoagulant activity not detected at concentrations tested (from 0.001 to $0.2 \mathrm{mg} / \mathrm{mL}$ ); - not determined; ${ }^{\mathrm{a}}$ Data are reported as concentration $(\mathrm{mg} / \mathrm{mL})$ required to double APTT compared to saline control.

In addition to the content of sulfate groups in polysaccharides, the positions of these groups in a monosaccharide residue also influenced the anticoagulant activity [21]. Here, SP from E. crassipes contained galactose-6-sulfate as observed in FT-IR, indicating this sulfated residue to be important for anticoagulant activity of this SP. In agreement with our results, Chaidedgumjorn et al. [22] showed that polysaccharides specifically desulfated at position C6 lost their anticoagulant activity, whereas desulfation on $\mathrm{C} 4$ did not affect polysaccharide anticoagulant activity.

E. crassipes is a very resilient plant that adapts well to many aquatic environments, including those affected by human activities. It is one of the most proliferate plant types and is easily cultivated, already colonizing 62 countries in Africa, Asia and North America, with human help. In some areas, E. crassipes is used in phytoremediation projects. However, in most cases it is considered a pest $[23,24]$. Identifying bioactive SP in this plant increases its potential use as source for developing anticoagulant 
drugs. Thus, in addition to this study, E. crassipes has been selected further for bioguided fractionation and isolation of active anticoagulant polysaccharides.

\section{Experimental Section}

\subsection{Plant Material}

The following plants were collected in the Agua Quente stream (05 $59^{\prime} \mathrm{S}$ and $\left.35^{\circ} 07^{\prime} \mathrm{W}\right)$, located in Parnamirim, Rio Grande do Norte state, Brazil: Eichhornia crassipes (Mart.) Solms (Liliopsida-Commelinales), Egeria densa Planch (Liliopsida-Alismatales), Egeria naja Planchon (Liliopsida-Alismatales), Cabomba caroliniana Gray (Magnoliopsida-Nymphaeales), Ceratophyllum sp. (Magnoliopsida-Ceratophyllales), Hydrocotyle bonariensis Comm. ex Lam. (Magnoliopsida-Apiales) and Nymphaea ampla (Salisb.) D.C. (Magnoliopsida-Nymphaeales). Specimens were identified by M. Iracema B. Loiola and deposited in the herbarium of the Center of Biosciences, Federal University of Rio Grande do Norte, Natal, Brazil, under catalog numbers 2260, 2259, 8107, 8105, 8106, 2258 and 2261 respectively.

The seaweeds Caulerpa sertularioides, Gracilaria caudata, and Dictyopteris delicatula were collected at Búzios Beach in Nísia Floresta-RN, Brazil. Algae were stored in our laboratory and dried at $50{ }^{\circ} \mathrm{C}$ with ventilation in an oven, ground in a blender and incubated with acetone to eliminate lipids and pigments.

\subsection{Extraction of Polysaccharides}

Plant samples were collected and transported to the laboratory in plastic bags containing river water. Plants were then cleaned and, when possible, each plant was divided into four parts: root, leaves, petiole and rhizome. Each part was dried at $50{ }^{\circ} \mathrm{C}$ with ventilation and ground in a blender. These materials were treated with acetone $(4 \mathrm{~L})$ in order to eliminate lipids and pigments. One hundred grams of each part, defatted, dry and powdered, were suspended with $500 \mathrm{~mL}$ of $0.25 \mathrm{M} \mathrm{NaCl}$, and the $\mathrm{pH}$ was adjusted to 8.0 with $\mathrm{NaOH}$. Twenty mg of maxatase, an alkaline protease from Esporobacillus (Biobras, MG, Brazil), was added to the mixture for proteolytic digestion. After $18 \mathrm{~h}$ of incubation at $60{ }^{\circ} \mathrm{C}$ under agitation, the mixture was filtered through cheesecloth. The filtrate was precipitated with 2 volumes of methanol and maintained at $4{ }^{\circ} \mathrm{C}$ during $24 \mathrm{~h}$. The precipitate formed after centrifugation $(10,000 \times \mathrm{g}, 20 \mathrm{~min}$.) was dried under vacuum and it was suspended in distilled water and then it was analyzed.

The sulfated polysaccharides from seaweed were obtained as described by Costa and colleagues [1].

\subsection{Chemical Analysis}

Total sugars were estimated using the phenol- $\mathrm{H}_{2} \mathrm{SO}_{4}$ reaction [25] with D-galactose as a base standard. After acid hydrolysis of polysaccharides $\left(4 \mathrm{~N} \mathrm{HCl}, 100{ }^{\circ} \mathrm{C}, 4 \mathrm{~h}\right)$, sulfate content was measured using the gelatin-barium method [26]. Polysaccharides were hydrolyzed with $0.5,1,2$, and $4 \mathrm{M}$ of $\mathrm{HCl}$, respectively, for varying periods of time $(0.5,1,2$ and $4 \mathrm{~h})$ at $100{ }^{\circ} \mathrm{C}$. Reducing sugars were determined using the Somogyi-Nelson method [27]. Following acid hydrolysis, sugar composition was determined by a LaChrom Elite ${ }^{\circledR}$ HPLC system from VWR-Hitachi with a refractive index detector 
(RI detector model L-2490). A LichroCART ${ }^{\circledR} 250-4$ column $(250 \mathrm{~mm} \times 40 \mathrm{~mm})$ packed with Lichrospher $^{\circledR} 100 \mathrm{NH} 2(5 \mu \mathrm{m})$ was coupled to the system. The sample mass used was $0.2 \mathrm{mg}$ and analysis time was $25 \mathrm{~min}$. The following sugars were analyzed as references: arabinose, fructose, fucose, galactose, glucose, glucosamine, mannose, rhamnose, and xylose. The amount of uronic acid was determined as described by Barroso et al. [28]. Protein content was measured using the methods described by Spector [29], with bovine albumin as standard.

\subsection{Agarose Gel Electrophoresis}

Agarose gel electrophoresis was prepared in $0.05 \mathrm{M}$ 1,3-diaminopropane-acetate buffer, at $\mathrm{pH} 9.0$ as previously described [17].

\subsection{Fourier Transform Infrared Spectroscopy (FT-IR)}

Sulfated polysaccharides $(5 \mathrm{mg}$ ) were mixed thoroughly with dry potassium bromide. A pellet was prepared and the infrared spectra between 500 and $4000 \mathrm{~cm}^{-1}$ were measured on a Thermo-Nicolet Nexus 470 ESP FT-IR spectrometer. Thirty-two scans at a resolution of $4 \mathrm{~cm}^{-1}$ were averaged and referenced against air.

\subsection{Histological Examination}

Plant samples were collected in the same area described above, transported to the laboratory in plastic bags containing river water and cleaned of other organisms. Fragments $5 \mathrm{~mm}$ in diameter were cut from the roots and immediately fixed in 70\% FAA mixture (formalin 40\%, alcohol $70 \%$, acetic acid) for $48 \mathrm{~h}$, and then conserved in $70^{\circ}$ G.L. ethyl alcohol. For anatomic analysis, these materials were dehydrated with acetone graded series followed by the addition of paraffin wax in accordance with standard techniques applied in plant anatomy. Sections $(10 \mu \mathrm{m})$ were obtained in a microtome (Sorvall, Asheville, NC) and stained with 1\% toluidine blue (Sigma), $\mathrm{pH} 4.4$, for $3 \mathrm{~min}$ at $40{ }^{\circ} \mathrm{C}$. This stain reveals the presence of sulfated polysaccharides by metachromasia [9].

\subsection{Scanning Electron Microscopy (SEM) and Energy-Dispersive X-ray Analysis (EDXA)}

Pieces of $\sim 9 \mathrm{~mm}^{2}$ from the roots of E. crassipes were cut with razor blades under a stereomicroscope and rinsed with a $0.1 \mathrm{M}$ cacodylic acid buffer, $\mathrm{pH} 7.4$ and kept at room temperature for $60 \mathrm{~min}$ in $2.5 \%$ glutaraldehyde. After washing in the cacodylic acid buffer, roots were post-fixed and contrasted for $1 \mathrm{~h}$ in $1 \%$ osmium tetroxide $(\mathrm{OsO} 4)$. Fixed roots were then dehydrated with increasing concentrations of ethanol, dried using the $\mathrm{CO}_{2}$ critical-point method, sputter-coated with gold and examined with a Shimadzu SSX-550 microscope.

Elemental composition of roots was determined by energy dispersive X-ray analysis (EDXA). Samples were prepared for MEV as described above, and analyzed on a Shimadzu SSX-550 equipped with a Noran-Voyager analytical system. A focused spot $(d \sim 100 \mathrm{~nm})$ was used to analyze areas of interest in the root sample. Areas probed were representative of the whole sample (we obtained several spectra from the individual particles). Micrographs were obtained from untilted samples (before analysis). During EDXA, the samples shown in this investigation were stable under the electron beam. 
Typical acquisition data were: accelerating voltage $=20 \mathrm{kV}$, live-time $=300 \mathrm{~s}$, dead-time $\sim 18 \%$, and sample tilt angle $=30^{\circ}$.

Chemical mapping was performed as described by Andrade et al. [30] using a Shimadzu SSX-550 microscope.

\subsection{Abiotic Factors}

Water from the Água Quente stream was collected at three different sites and $\mathrm{pH}$ and salinity of each solution were determined using a PHTEK pHS-3B pH meter and an RTS 101 ATC refractometer, respectively.

\subsection{Proximate Composition}

Proteins, carbohydrate, lipids, ash, moisture and nitrogen contents of plants were determined by standard AOAC (1995) [31] methods. Protein content was calculated by converting the nitrogen content, determined by the micro-Kjeldahl method $(6.25 \cdot \mathrm{N})$. Carbohydrate content was determined as the weight difference using protein, lipid, fiber, moisture and ash content data. Lipids from plant powder were extracted in a Soxhlet extractor (TECNAL-TE-044, São Paulo, BR) using hexane. The residue was re-extracted, after being washed with boiling distilled water and acetone and finally dried at $105{ }^{\circ} \mathrm{C}$ to constant weight. The material was heated at $550{ }^{\circ} \mathrm{C}$ for $3 \mathrm{~h}$ and the weight recorded. Moisture content was established by drying the plant samples in an oven at $105{ }^{\circ} \mathrm{C}$ until a constant weight was obtained. Ash content was obtained by calcinations in a muffle furnace at $550{ }^{\circ} \mathrm{C}$ for $4 \mathrm{~h}$.

\subsection{Genomic Analyses}

BLAST analysis was performed at NCBI [32] as described for Altschul and colleagues [33]. Nucleotide and protein sequences from Homo sapiens, Rattus norvegicus, Mus musculus, Cricetulus longicaudatus, Drosophila melanogaster, Mus sp., Flaveria bidentis, Rhizobium sp. were used as probes for this search. Homologous sequences were then researched in plant databases at NCBI GenBank [32], TAIR [34], TIGR [35]. Additionally, sequences M92042; U17970 and U02304 were used to search for 5'PSB and 3'PB in the conserved protein region for sulphotransferase. Primers were designed using these motifs. E. crassipes DNA was extracted as described for Doyle and Doyle [36]. PCR reactions were performed using $100 \mathrm{ng}$ of DNA and PCR conditions were as follows: 3 min at $95{ }^{\circ} \mathrm{C}$, then 35 cycles of $95{ }^{\circ} \mathrm{C} 30 \mathrm{~s}, 50-62{ }^{\circ} \mathrm{C} 30 \mathrm{~s}$ (non-stringent or stringent temperature condition), $72{ }^{\circ} \mathrm{C} 30 \mathrm{~s}$, and then $72{ }^{\circ} \mathrm{C}$ for $5 \mathrm{~min}$. Taq polymerase (Invitrogen) was used in these reactions, and the primers were: P1F 5'-TCT ACC TAT GAG CCA GTG CTG-3', P1R 5'-CAG AGG TGG TGT TGG AGG GAA TGA-3', P2R 5'-CTG AGC CAG CGT TCA ATA TGA GTG-3', PF 5'-AGG AGA AGA CAT GTG ATC GCT TCC-3' and PR 5'-CCA GCG TTC AAT ATG AGT GGC ATA-3'. The amplified fragments were separated on a $0.8 \%$ agarose gel.

\subsection{Anticoagulant Activity}

All protrombin time (PT) and activated partial thromboplastin time (APTT) coagulation assays were performed with a coagulometer as previously described [37], and measured using citrate treated 
normal human plasma. All assays were performed in duplicate and repeated at least three times on different days $(n=6)$.

\section{Conclusions}

In conclusion, we found sulfate in polysaccharide-rich extracts of three freshwater plants: E. crassipes, $N$. ampla and H. bonariensis. All parts of E. crassipes synthesize SP; however, significant amounts were only recorded in the roots. We extracted SP from E. crassipes, which showed anticoagulant activity at different levels. It is evident that the biological function of SP is dependent on its structural characteristics. Additional investigation will identify and purify active polysaccharides in E. crassipes to further our understanding of the complete polysaccharide structure, including the composition and sequence of monosaccharides, the configuration and position of glycosidic linkages, the position of branching points and the structure-function relationship. This will certainly provide a promising opportunity to elucidate the biological roles of polysaccharides and develop potential anticoagulant drugs based on the three-dimensional structures.

\section{Acknowledgements}

We wish to thank the CNPq, CAPES, FAPERN/CNPq and MCT for their financial support in the form of grants and fellowship awards. SL Cordeiro, MSSP Costa, DG Santos and ND-Santos are grateful to the CNPq and CAPES for fellowship support. This research was submitted to the Graduate Program in Health Sciences at the Federal University of Rio Grande do Norte as part of the D. Sc. thesis of ND-S.

\section{References}

1. Costa, L.S.; Fidelis, G.P.; Cordeiro, S.L.; Oliveira, R.M.; Sabry, D.A.; Câmara, R.B.G.; Nobre, L.T.D.B.; Costa, M.S.S.P.; Almeida-Lima, J.; Farias, E.H.C.; et al. Biological activities of sulfated polysaccharides from tropical seaweeds. Biomed. Pharmacother. 2010, 64, 21-28.

2. Jiao, G.; Yu, G.; Zhang, J.; Ewart, H.S. Chemical structures and bioactivities of sulfated polysaccharides from marine algae. Mar. Drugs 2011, 9, 196-223.

3. Medeiros, G.F.; Mendes, A.; Castro, R.A.B.; Baú, E.C.; Nader, H.B.; Dietrich, C.P. Distribution of sulfated glycosaminoglycans in the animal kingdom: Widespread occurrence of heparin-like compounds in invertebrates. Biochim. Biophys. Acta 2000, 1475, 287-294.

4. Dreyfuss, J.L.; Regatieri, C.V.; Jarrouge, T.R.; Cavalheiro, R.P.; Sampaio, L.O.; Nader, H.B. Heparan sulfate proteoglycans: Structure, protein interactions and cell signaling. An. Acad. Bras. Cienc. 2009, 81, 409-429.

5. Michel, G.; Tonon, T.; Scornet, D.; Cock, J.M.; Kloareg, B. The cell wall polysaccharide metabolism of the brown alga Ectocarpus siliculosus. Insights into the evolution of extracellular matrix polysaccharides in Eukaryotes. New Phytol. 2010, 188, 82-97.

6. Usov, A.I. Polysaccharides of the red algae. Adv. Carbohydr. Chem. Biochem. 2011, 65, 115-217. 
7. Costa, L.S.; Telles, C.B.S.; Oliveira, R.M.; Nobre, L.T.D.B.; Dantas-Santos, N.; Camara, R.B.G.; Costa, M.S.S.P.; Almeida-Lima, J.; Melo-Silveira, R.F.; Albuquerque, I.R.L.; et al. Heterofucan from Sargassum filipendula induces apoptosis in HeLa cells. Mar. Drugs 2011, 9, 603-614.

8. Ciancia, M.; Quintana, I.; Cerezo, A.S. Overview of anticoagulant activity of sulfated polysaccharides from seaweeds in relation to their structures, focusing on those of green seaweeds. Curr. Med. Chem. 2010, 17, 2503-2529.

9. Aquino, R.S.; Landeira-Fernandez, A.M.; Valente, A.P.; Andrade, L.R.; Mourão, P.A. Occurrence of sulfated galactans in marine angiosperms: Evolutionary implications. Glycobiology 2005, 15, $11-20$.

10. Aquino, R.S.; Grativol, C.; Mourão, P.A. Rising from the sea: Correlations between sulfated polysaccharides and salinity in plants. PLoS One 2011, 6, doi:10.1371/journal.pone.0018862.

11. Nader, H.B.; Medeiros, M.G.L.; Paiva, J.F.; Paiva, V.M.P.; Jerônimo, S.M.B.; Ferreira, T.M.P.C.; Dietrich, C.P. A correlation between the sulfated glycosaminoglycan concentration and degree of salinity of the "habitat" in fifteen species of the classes Crustacea, Pelecypoda and Gastropoda. Comp. Biochem. Physiol. B 1983, 76, 433-436.

12. Henry-Silva, C.G.; Camargo, A.F.M. Chemical composition of floating aquatic macrophytes used to treat of aquaculture wastewater. Planta Daninha 2006, 24, 21-28.

13. Farias, E.H.; Pomin, V.H.; Valente, A.P.; Nader, H.B.; Rocha, H.A.O.; Mourão, P.A. A preponderantly 4-sulfated, 3-linked galactan from the green alga Codium isthmocladum. Glycobiology 2008, 18, 250-259.

14. Silva, T.M.A.; Alves, L.G.; Queiroz, K.C.S.; Santos, M.G.L.; Marques, C.T.; Chavante, S.F.; Rocha, H.A.O.; Leite, E.L. Partial characterization and anticoagulant activity of a heterofucan from the brown seaweed Padina gymnospora. Braz. J. Med. Biol. Res. 2005, 38, 523-533.

15. Ghosh, P.; Adhikari, U.; Ghosal, P.K.; Pujol, C.A.; Carlucci, M.J.; Damonte, E.B.; Ray, B. In vitro anti-herpetic activity of sulfated polysaccharide fractions from Caulerpa racemosa. Phytochemistry 2004, 65, 3151-3157.

16. Wang, X.; Wang, J.; Zhang, J.; Zhao, B.; Yao, J.; Wang, Y. Structure-antioxidant relationships of sulfated galactomannan from guar gum. Int. J. Biol. Macromol. 2010, 46, 59-66.

17. Dietrich, C.P.; Dietrich, S.M. Electrophoretic behaviour of acidic mucopolysaccharides in diamine buffers. Anal. Biochem. 1976, 70, 645-647.

18. Camara, R.B.G.; Costa, L.S.; Fidelis, G.P.; Nobre, L.T.D.B.; Dantas-Santos, N.; Cordeiro, S.L.; Costa, M.S.S.P.; Alves, L.G.; Rocha, H.A.O. Heterofucans from the brown seaweed Canistrocarpus cervicornis with anticoagulant and antioxidant activities. Mar. Drugs 2011, 9, 124-138.

19. Li, B.; Lu, F.; Wei, X.; Zhao, R. Fucoidan: Structure and bioactivity. Molecules 2008, 13, 1671-1695.

20. Bilan, M.I.; Usov, A.I. Structural analysis of fucoidans. Nat. Prod. Commun. 2008, 3, 1639-1648.

21. Mestechkina, N.M.; Shcherbukhin, V.D. Sulfated polysaccharides and their anticoagulant activity: A review. Appl. Biochem. Microbiol. 2010, 46, 267-273.

22. Chaidedgumjorn, A.; Toyoda, H.; Woo, E.R.; Lee, K.B.; Kim, Y.S.; Toida, T.; Imanari, T. Effect of (1-3)- and (1-4)-linkages of fully sulfated polysaccharides on their anticoagulant activity. Carbohydr. Res. 2002, 337, 925-933. 
23. Malik, A. Environmental challenge vis a vis opportunity: The case of water hyacinth. Environ. Int. 2007, 33, 122-138.

24. Jayaweera, M.W.; Kasturiarachchi, J.C.; Kularatne, R.K.A.; Wijeyekoon, S.L.J. Contribution of water hyacinth (Eichhornia crassipes (Mart.) Solms) grown under different nutrient conditions to Fe-removal mechanisms in constructed wetlands. J. Environ. Manag. 2008, 87, 450-460.

25. Dubois, M.; Gilles, K.A.; Hamilton, J.K.; Rebers, P.A.; Smith, F. Colorimetric method for determination of sugars and related substances. Anal. Chem. 1956, 28, 250-256.

26. Dodgson, K.S.; Price, R.G. A note on the determination of the ester sulphate content of sulphated polysaccharides. Biochem. J. 1962, 84, 106-110.

27. Somogyi, M. Notes on sugar determination. J. Biol. Chem. 1952, 195, 19-23.

28. Barroso, E.M.A.; Costa, L.S.; Medeiros, V.P.; Cordeiro, L.S.; Costa, M.S.S.P.; Franco, C.R.C.; Nader, H.B.; Leite, E.L.; Rocha, H.A.O. A Non-Anticoagulant Heterofucan has Antithrombotic Activity in vivo. Planta Med. 2008, 74, 712-718.

29. Spector, J. Refinement of the coomassie blue method of protein quantification. A simple and linear spectrophotometric assay of 0.5 to $50 \mu \mathrm{g}$ of protein. Anal. Biochem. 1978, 86, 142-143.

30. Andrade, R.A.; Salgado, L.T.; Farina, M.; Pereira, M.S.; Mourao, P.A.S.; Filho Amado, G.M. Ultrastructure of acidic polysaccharides from the cell walls of brown algae. J. Struct. Biol. 2004, $145,216-225$.

31. AOAC. Official Methods of Analysis of the Agriculture Chemistry; Willian Horwitz: Washington, DC, USA, 1985.

32. Altschul, S.F.; Gish, W.; Miller, W.; Myers, E.W.; Lipman, D.J. Basic local alignment search tool. J. Mol. Biol. 1990, 215, 403-410.

33. National Center for Biotechnology Information-NCBI. Available online: http://www.ncbi.nlm.nih.gov (accessed on 12 April 2010).

34. The Arabidopsis Information Resource-TAIR. Available online: http://www.arabidopsis.org (accessed on 22 May 2010).

35. TIGR Plant Transcript Assemblies. Available online: http://plantta.jcvi.org (accessed on 7 June 2010).

36. Doyle, J.J.; Doyle, J.L. Isolation of plant DNA from fresh tissue. Focus 1990, 12, 13-15.

37. Magalhaes, K.D.; Costa, L.S.; Fidelis, G.P.; Oliveira, R.M.; Nobre, L.T.B.; Dantas-Santos, N.; Camara, R.B.; Albuquerque, I.R.; Cordeiro, S.L.; Sabry, D.A.; et al. Anticoagulant, antioxidant and antitumor activities of heterofucans from the seaweed Dictyopteris delicatula. Int. J. Mol. Sci. 2011, 12, 3352-3356.

(C) 2012 by the authors; licensee MDPI, Basel, Switzerland. This article is an open access article distributed under the terms and conditions of the Creative Commons Attribution license (http://creativecommons.org/licenses/by/3.0/). 